Vanitas und Gesellschaft 



\section{Vanitas und Gesellschaft}

Herausgegeben von

Claudia Benthien, Antje Schmidt und Christian Wobbeler 
Die Arbeit an dem Forschungsprojekt „Vanitas in den Künsten der Gegenwart“ wird von der Fritz Thyssen Stiftung gefördert.

ISBN 978-3-11-071595-8

e-ISBN (PDF) 978-3-11-071601-6

e-ISBN (EPUB) 978-3-11-071605-4

DOI https://doi.org/10.1515/9783110716016

\section{(cc) BY-NC-ND}

Dieses Werk ist lizensiert unter einer Creative Commons Namensnennung-Nicht-kommerziellKeine Bearbeitung 4.0 International Lizenz. Weitere Informationen finden Sie unter http://creativecommons.org/licenses/by-nc-nd/4.0/.

\section{Library of Congress Control Number: 2021937477}

\section{Bibliografische Information der Deutschen Nationalbibliothek}

Die Deutsche Nationalbibliothek verzeichnet diese Publikation in der Deutschen Nationalbibliografie; detaillierte bibliografische Angaben sind im Internet über http://dnb.dnb.de abrufbar.

(c) 2021 bei den Autorinnen und Autoren, Konzeption und Herausgabe (c) 2021 Claudia Benthien, Antje Schmidt und Christian Wobbeler, publiziert von Walter de Gruyter.

Dieses Buch ist als Open-Access-Publikation verfügbar über www.degruyter.com.

Cover: Quatre Caps: „Abraham Van Beyeren“ aus der Serie Not Longer Life, Fotografie, 2019.

(c) Quatre Caps. Mit freundlicher Genehmigung der Künstler.

Satz: Integra Software Services Pvt. Ltd.

Druck und Bindung: CPI books $\mathrm{GmbH}$, Leck

www.degruyter.com 